Fecha de recepción: abril 2020 Fecha de aceptación: mayo 2020 Versión final: junio 2020

\section{Prólogo. Visualidades expandidas y narrativas transmediales: derivas de las artes, los lenguajes y los medios}

Maximiliano de la Puente ${ }^{(1)}$ y Laura Vazquez ${ }^{(2)}$

Resumen: El presente volumen reúne trabajos que reflexionan desde y a partir de las artes plásticas, visuales y videográficas contemporáneas, además de otras prácticas relacionadas que dialogan o entran en controversia con los regímenes de representación propios de la modernidad en tanto esferas autónomas y separadas. Son textos que entablan conversaciones con distintas perspectivas estéticas y que hacen hincapié en diversas gramáticas y regímenes escópicos. Lo que tienen en común es que piensan cómo las visualidades (plásticas, audiovisuales, gráficas) se expanden a través de las nuevas pantallas y espacios modificando ontológicamente lo que entendemos por artes y narrativas visuales, cinematográficas o de cualquier otro tipo.

Palabras clave: narrativas contemporáneas - artes gráficas - lenguaje - imagen - medios de comunicación.

[Resúmenes en inglés y portugués en la página 16]

(1) Dr. Maximiliano de la Puente (CONICET-IIGG-UBA; ICSE-UNTDF, CRÍTICA DE ARTES-UNA; UNTREF).

(2) Dra. Laura Vazquez (CONICET-IIGG-UBA; UNIVERSIDAD DE PALERMO, CRÍTICA DE ARTES-UNA; UNM, UTDT).

Una breve presentación de la coordinación conjunta de este Cuaderno del Centro de Estudios de Diseño y Comunicación de la Universidad de Palermo. Somos investigadores del CONICET y egresados de la Universidad de Buenos Aires con pertenencia institucional a un lado y otro del territorio nacional. Desde Buenos Aires (Laura Vazquez) a Tierra del Fuego (de la Puente) hemos tendido un puente en el tiempo y en el espacio para pensar desde distintos prismas teóricos y metodológicos los distintos fenómenos críticos de la cultura visual actual. La dimensión geográfica no es un tema menor en nuestro criterio analitico. A menudo en nuestras disciplinas del diseño y la comunicación se analizan los dispositivos, objetos, soportes y medios de manera concéntrica sin atender las tensiones entre lo global, lo glocal y lo regional. Entendemos que la manera de subsanar la tensión 
integración-dependencia científica/académica es trabajando de manera radial entre investigadores pertenecientes a unidades académicas que recorran todo el arco del territorio nacional. Temas como las sincronías y disparidades nacionales, las temporalidades divergentes, las desigualdades y correlaciones regionales merecen un abordaje crítico y enfático en términos metodológicos. El desarrollo de nuevos medios interactivos posibilita y exige una revisión de los modos tradicionales de diseñar y producir los artefactos culturales, como así también de las perspectivas teóricas que los estudian y sistematizan.

De allí que el presente volumen reúne trabajos que reflexionan desde y a partir de las artes plásticas, visuales y videográficas contemporáneas, además de otras prácticas relacionadas que dialogan o entran en controversia con los regímenes de representación propios de la modernidad en tanto esferas autónomas y separadas. Son textos que entablan conversaciones con distintas perspectivas estéticas y que hacen hincapié en diversas gramáticas y regímenes escópicos. Lo que tienen en común es que piensan cómo las visualidades (plásticas, audiovisuales, gráficas) se expanden a través de las nuevas pantallas y espacios, modificando ontológicamente lo que entendemos por artes y narrativas visuales, cinematográficas o de cualquier otro tipo.

Una reflexión central que los aglutina es el rol de la autoría en tiempos contemporáneos, teniendo en cuenta las condiciones culturales, políticas, económicas o tecnológicas en las que las obras y producciones tienen o tuvieron lugar. Los artículos abordan también las diversas mutaciones que han transformado en los últimos años a las narrativas expandidas visuales, plásticas y gráficas contemporáneas, además de hacer hincapié en los deslindes de las artes, los lenguajes y los géneros.

En este sentido son apuestas que a partir de continuidades y rupturas entre lenguajes, géneros, soportes mediáticos y pertenencias estilísticas corren los límites de lo decible y lo institucional heredado como forma instituida del arte. Son trabajos que valoran las descripciones e interpretaciones y que analizan las visualidades expandidas de manera confrontativa, comparativa y divergente. El método de estos abordajes no podría ser sino polisémico, herméutico y transdisciplinario y en donde convive lo erudito y lo popular, los registros de lo alto y lo bajo, lo emergente y lo instituido de manera transversal y articulada. A continuación describimos brevemente las aproximaciones de los distintos aportes. Pensamos en una organización en dos grandes temas o bloques, la primera centrada en los resultados de diversos trabajos de tesis a nivel posgrado. Es el caso de los artículos de Agustín García Serventi, Martín Tissera, Eugenia Basualdo, Fabio Bortolazzo Pinto, Carolina Corti, Iván Abadia y Aluminé Rosso. Los trabajos de Lorena Díaz Quiroga, Malala González, Facundo Diéguez, Paula La Rocca, Chantal Arduini Amaya, Edén Bastida Kullick y Nayeli Benhumea Salto, integran por su parte diversas investigaciones en curso que tienen también por objeto las visualidades contemporáneas.

Agustín García Serventi, de la Universidad Nacional de Tierra del Fuego, Antártida e Islas del Atlántico Sur y de la Facultad de Arquitectura, Diseño y Urbanismo de la Universidad de Buenos Aires, en su artículo Abordajes teórico críticos en la instalación audiovisual. La teoría del tiempo libre y una estética desde la perspectiva del diseño, sostiene que las mutaciones que culminan en el ingreso de la tecnología digital computacional al campo del arte de instalación y su vertiente audiovisual, proponen un amplio abanico de abordajes a la hora de pensar el proyectar una obra: las operaciones de sentido que despliegan los 
artistas, así como los modos de experimentación que estos espacios proponen a quien la recibe se ven completamente modificados.

Martín Tissera, de la Facultad de Arquitectura, Diseño y Urbanismo de la Universidad de Buenos Aires y egresado de la Maestría en Diseño Comunicacional (DICOM), desarrolla en su trabajo Steampunk: análisis del carácter crítico de sus producciones objetuales, la genealogía de este concepto que buscaba contextualizar las obras que transcurrían en el futuro imaginado por los escritores de ciencia ficción Julio Verne y H. G. Wells, a finales del siglo XIX. Convertido en una subcultura en la década de 1990, el Steampunk recupera para su estética elementos de la máquina victoriana. Tissera señala que este procedimiento puede observarse hoy, y cada vez con mayor frecuencia, en los diferentes ámbitos de la producción visual. El análisis se propone analizar los modos en que algunos de los objetos producidos por esta subcultura adquieren una dimensión crítica.

Eugenia Basualdo, perteneciente a la Universidad Nacional de las Artes y magíster por dicha institución en el área de Crítica y Difusión de las Artes, en su artículo El siglo XXI: la curaduría como el boom del momento y los libros específicos, analiza las publicaciones específicas sobre la práctica curatorial surgidas entre 2002 y 2017 en la Argentina desde un enfoque crítico, constituyéndose así en un aporte destacado para una apreciación de los avances en los estudios sobre la curaduría a nivel local. Como señala la autora, en el campo del arte argentino contemporáneo la curaduría se instala como práctica a partir de la década de 1980. Sin embargo, su estudio teórico-crítico como disciplina se inicia en el país recién a comienzos del siglo XXI; de allí su creciente y reciente interés como campo de investigación con dinámica propia.

Fabio Bortolazzo Pinto, de la Universidade Federal do Vale do Rio Dos Sinos de Sao Paulo, en su trabajo Una historieta expandida o como El Eternauta me apresentou à pátria grande, estudia el ya mítico relato de Héctor Germán Oesterheld. Este trabajo abarca aspectos simbólicos de El Eternauta, a partir de los que el autor propone reflexiones críticas en relación a la historia política de Argentina y del continente. El proceso de investigación, desarrollado en el área de Ciencias de la Comunicación, en confluencia con los Estudios Literarios, la Filosofía y la Historia, constituye también un proceso de conocimiento y familiarización con un patrimonio cultural común, oculto bajo las diferentes experiencias coloniales de Brasil y Argentina.

Carolina Corti, de la Facultad de Arquitectura, Diseño y Urbanismo de la Universidad de Buenos Airesy egresada de la Maestría en Diseño y Comunicación (DICOM), en el escrito De la representación teatral a la exhibición de arquitectura (1957-1970). Situacionismo, utopismo y posmodernismo, recorre el lugar que tuvo la exhibición de arquitectura como fenómeno ligado a las nociones de experiencia, percepción y lenguaje. Este camino histórico atraviesa algunos hitos importantes para la temática, como la creación del movimiento Internacional Situacionista, el legado del grupo Archigram y los nuevos debates a la luz de los paradigmas posmodernistas. El artículo se enmarca en una tesis que plantea la importancia de analizar la producción de la arquitectura -usualmente materializada a través del "hacer arquitectónico"- abordando sus significados por fuera de la materialización de la obra.

Iván Abadia, de la Facultad de Arquitectura, Diseño y Urbanismo de la Universidad de Buenos Aires y Magíster en Diseño Comunicacional (DICOM), en su artículo 'Vamo a 
calmarno'. Los memes como dispositivos de referencialidad comunicativa, desarrolla una posible definición de los memes como prácticas de referencialidad, a través de la proposición de un modelo metalingüístico que permita explicar de qué forma se relacionan dichas imágenes digitales con los complejos procesos comunicativos en las que se ven envueltas. De esa manera, la autora realiza un significativo aporte a la definición del meme digital como concepto teórico, y propone otras/nuevas categorías de comprensión sobre la utilización de imágenes meméticas en prácticas comunicativas mediadas por lo digital.

Aluminé Rosso, egresada de la Maestría en Crítica y Difusión de las Artes de la Universidad de las Artes, en \#ArteContemporáneo: La arquitectura del museo de arte moderno como discursividad intermediaria. Un análisis de la promesa experiencial configurada por los edificios de Centro Pompidou, Malba, Moma y Tate Modern expone el proceso de elaboración de la investigación desarrollada en el marco de la Maestría en Crítica y difusión de las Artes (UNA), y se focaliza en la selección del corpus, en el diseño metodológico, la planificación y las conclusiones del análisis de terreno desarrollado entre 2016 y 2019 . El artículo se concentra en los casos Malba (Buenos Aires), Moma (Nueva York), Tate Modern (Londres), y Centre Pompidou (París), en sus fachadas, explanadas y halls entendidos como discursividades intermediarias que configuran una promesa experiencial a los visitantes, puesto que estos espacios adelantan, sugieren o informan algo sobre aquello que el público experimentará al interior de los edificios.

Lorena Díaz Quiroga, de la Universidad Nacional de Tierra del Fuego, Antártida e Islas del Atlántico Sur y de la Universidad Nacional de San Martín, desarrolla en su artículo Museo de la inmortalidad. Apuntes para un ensayo transmedia una propuesta de ensayo interactivo a partir de las teorías biocosmistas soviéticas y la percepción de la relación entre vida y muerte por parte de las culturas occidentales. El trabajo avanza en la explicitación de un exhaustivo y fascinante marco teórico en pos de la elaboración de un futuro ensayo audiovisual en formato interactivo y de docuficción sobre el tema señalado.

Malala González, de la Facultad de Filosofía y Letras de la Universidad de Buenos Aires, en su trabajo Arte público contemporáneo y la puerta bicentenaria del GAC. ¿Hasta dónde es posible seguir hablando de monumentos?, aborda los festejos del Bicentenario nacional argentino, que tuvo lugar en mayo de 2010. El espacio público intervenido artísticamente para la ocasión le permite reflexionar sobre las narrativas visuales expandidas por la ciudad en esos días. La autora sostiene que la puesta del Grupo de Arte Callejero (GAC) problematiza la condición material del recuerdo, en tanto artefacto efímero, entablando una correlación con el contexto sociopolítico en el que tuvo lugar. De esta manera, González propone pensarla como una práctica de memoria contemporánea mediante la cual las categorías de lo monumental/contramonumental resultan convergentes con una percepción de la ciudad interpeladora y performática.

Facundo Diéguez, becario posdoctoral del Consejo Nacional de Investigaciones Científicas y Técnicas (CONICET), y perteneciente también a la Universidad Nacional de las Artes y a la Universidad Nacional de La Plata, en Plataformas mediáticas de los museos de artes visuales: mediación técnica, mediatización e interdisciplina, analiza el modo en que el museo se transforma a partir de la caída del sistema tradicional de medios y la reconfiguración paulatina dada por el despliegue de la lógica transmedia y de las redes sociales. Diéguez indaga también en el lugar que estos fenómenos tienen en las artes contempo- 
ráneas y en sus abordajes teóricos y analíticos, y se pregunta por cómo la mediatización llevada a cabo por los museos de artes visuales provoca cambios de escala en la acción performática de diversos espacios sociales dedicados a la exhibición de propuestas artísticas, centrándose en el Museo de Arte Latinoamericano de Buenos Aires (MALBA) y en el Museo Nacional de Bellas Artes (MNBA) principalmente.

Paula La Rocca, Licenciada en Letras por la Universidad Nacional de Córdoba y becaria doctoral del CONICET, en su aporte Espacialidad en el conceptualismo latinoamericano. El caso Mirtha Dermisache busca dar cuenta de cómo las expresiones del arte de fines del Siglo XX están marcadas por una transformación de la relación material con el espacio. Su hipótesis es que ante un nuevo orden mundial en ascenso, posterior a la Segunda Guerra Mundial, las nuevas tendencias estéticas ponen de manifiesto un cruce muy sintomático entre la expresión de un territorio cada vez más global, la nueva expresión político-económica de la administración del mundo y las posibilidades técnicas que sostienen esa escala planetaria. De allí que ponga en evidencia que, específicamente bajo los conceptualismos, ese nuevo modelo de espacio se trabaja sobre los soportes estéticos incluso antes del salto técnico decisivo del siglo: la aparición de Internet.

Chantal Arduini Amaya, Licenciada en Comunicación Social por la Universidad Nacional de Quilmes, Doctoranda en Comunicación por la Universidad Nacional de La Plata y docente en la Universidad Nacional Guillermo Brown, en su trabajo Ficción transmedia en Argentina. El caso de la serie Según Roxi, analiza el caso Según Roxi. Originada como serie web en 2012, la ficción ha expandido su relato en diversas plataformas, agregando en la mayoría de ellas, elementos innovadores propios de esta nueva manera de contar historias. Desde un diseño de investigación cualitativa con la ayuda de la estrategia del estudio de caso y las técnicas de la observación y descripción, la investigación estudia tanto el canon como el fandom que integra el universo de Roxi.

Edén Bastida Kullick, artista e investigador, y Doctor en Teoría e Historia de las Artes por la Universidad de Buenos Aires, en su trabajo Las proyecciones públicas de Krzysztof Wodiczko: arte público, monumento y victimización, aborda la obra de un referente clave a nivel global a la hora de pensar las proyecciones en el espacio público: Krzysztof Wodiczko. La línea de trabajo de Wodiczko es inmensa y variada, pero casi en su totalidad y de manera continua ha estado presente de algún modo lo concerniente al arte público. Haciendo foco en sus intervenciones audiovisuales, Bastida Kullick retoma una serie de piezas que Wodiczko nombra Proyecciones Públicas, y que desarrolla desde los años ochenta hasta la actualidad. Estas piezas son acciones proyectivas sobre edificios públicos, monumentos y arquitectura urbana en las que la unión de imagen y receptáculo -en este caso la superficie arquitectónica- contienen y posibilitan una multiplicidad de significantes y, en algunos casos, un choque dialéctico conceptual con el fin de ejercer un proceso reflexivo.

Finalmente, Nayeli Benhumea Salto, artista escénica, diseñadora gráfica y docente, y el propio Edén Bastida Kullick, en su trabajo Pizzurno Pixelado: entre la danza y el premapping, analizan la video-instalación que la reconocida coreógrafa, artista visual y docente Margarita Bali, realizó en 2005 sobre la fachada del Palacio Pizzurno en la ciudad de Buenos Aires, en el marco del Festival Internacional de Teatro, FIBA. La pieza integraba la danza y la música en vivo con el video y la proyección de imágenes y animaciones pregrabadas, constituyéndose como uno de los ejemplos más destacados en los últimos años 
de intervención de la danza en el espacio público, mediante la utilización de tecnología digital, proponiendo así un cruce interdisciplinario de lenguajes y disciplinas.

En resumen, este volumen aborda distintas problemáticas con diferentes grados de complejidad, desarrollo y posibilidades de expansión. Se trata de un volumen heterógeneo e interdisplinar, que intenta recorrer distintos objetos y temas cuyas relaciones traman relaciones de sentido alrededor de un eje vertebrador: aquellas narrativas y visualidades de la contemporaneidad que exigen, hoy más que en ningún momento histórico, nuestra plena atención y puesta en discusión. Al mismo tiempo, buscamos que esta edición reúna abordajes producidos por investigadores e investigadoras formados y formadas en disciplinas diversas y habitantes del amplio territorio nacional. Insistimos que ha sido el espiritu de esta edición la transversalidad geográfica y disciplinar. Esperamos disfruten de la empresa y compartan los límites del desafío.

\begin{abstract}
This volume is the result of articles that analyze from and starting with contemporary plastic, visual and videographic arts, in addition to other related practices that dialogue or come into controversy with the regimes of representation proper to modernity, as autonomous and separate disciplines. They are texts that engage in conversations with different aesthetic perspectives and that emphasize various grammars and scopic regimes. What they have in common is that they think about how visuals (plastic, audiovisual, graphic) expand through new screens and spaces ontologically modifying what we understand by visual, cinematographic or any other arts and narratives.
\end{abstract}

Keywords: contemporary narratives - graphics - language - image - mass media.

Resumo: Este volume é o resultado de artigos que analisam e começam com artes plásticas, visuais e videográficas contemporâneas, além de outras práticas relacionadas que dialogam ou entram em controvérsia com os regimes de representação próprios da modernidade, como disciplinas autônomas e separadas. São textos que dialogam com diferentes perspectivas estéticas e enfatizam várias gramáticas e regimes escópicos. O que eles têm em comum é que pensam em como o visual (plástico, audiovisual, gráfico) se expande através de novas telas e espaços, modificando ontologicamente o que entendemos por artes e narrativas visuais, cinematográficas ou quaisquer outras.

Palavras chave: narrativas contemporâneas - artes gráficas - linguagem - imagem - meios de comunicação.

[Las traducciones de los abstracts fueron supervisadas por el autor de cada artículo] 